\title{
Comunicación estratégica para la educación ambiental en entornos locales: Ámbito universitario
}

\author{
Andrea Estupiñán Villanueva, * Hilda Gabriela Hernández. \\ Flores, ** y Rosa Elba Domínguez Bolaños *** \\ Benemérita Universidad Autónoma de Puebla
}

\begin{abstract}
Resumen: El cambio climático y los diversos desastres naturales que acontecen en el planeta dan cuenta de la inconsciencia con la que hemos actuado en el pasado. En este sentido, la Benemérita Universidad Autónoma de Puebla asume su compromiso y trabaja arduamente para revertir en la medida de lo posible esta situación. Dentro de este capítulo se muestra el trabajo multidisciplinar y colegiado de un grupo de investigadores que con sus propuestas aportan soluciones a los problemas relacionados con el medio ambiente, siendo la comunicación elemento indispensable para la generación de una cultura socialmente responsable al interior de la comunidad universitaria.
\end{abstract}

Palabras clave: Comunicación, medio ambiente, desarrollo sostenible, educomunicación, responsabilidad social.

\begin{abstract}
Climate change and various natural disasters that befall our planet realize the unconsciousness with which we have acted in the past. In this sense, the Autonomous University of Puebla takes its commitment and work hard to reverse as far as possible the situation. Throughout this chapter shows the work of a multidisciplinary and collegial group of researchers that their proposals offer solutions to problems related to the environment, communication being the essential element for the generation of a socially responsible culture within the university community.
\end{abstract}

\footnotetext{
* Andrea Estupiñán Villanueva-maestría en comunicación y diseño gráfico. Investigadora de la Benemérita Universidad Autónoma de Puebla. anesvi02@hotmail.com ** Hilda Gabriela Hernández Flores- Maestría en marketing y negocios internacionales. Investigadora de la Benemérita Universidad Autónoma de Puebla. gaby_hf@yahoo.com.mx *** Rosa Elba Domínguez Bolaños-maestría en educación superior. Investigadora de la Benemérita Universidad Autónoma de Puebla-roshelb@hotmail.com
} 
Keywords: Communication, environment, sustainable development, educommunication, social responsibility.

\section{NACE UNA PROPUESTA DE VIDA}

El siglo XXI marca la fase de la ocupación por el medio ambiente, de evaluar los logros de los mensajes mediáticos y gubernamentales en este sentido, así como el impacto en la mente de los individuos, pues las cifras en deforestación, pérdida de mantos freáticos, deshielo de los polos, y temas similares, se han convertido en el encabezado de todo medio noticioso.

La Benemérita Universidad Autónoma de Puebla (BUAP), no se mantiene al margen y decide participar en el desarrollo de productos dirigidos al cuidado ambiental, a una mejor calidad de vida; es decir, a preservar la supervivencia de las especies dentro de un mismo ambiente, situaciones que nos atañen a todos para el mejoramiento de la calidad de vida.

El término calidad de vida no está directamente relacionado con ingreso económico ni reconocimiento social; calidad de vida debe ser entendido como toda aquella acción que aporta un beneficio al diario vivir de un grupo de individuos, que por ser de naturaleza social, deben mantenerse en la preocupación de conservar en condiciones benéficas el medio ambiente en el que nos desarrollamos.

Determinar y diagnosticar la mejor manera de entender el daño ambiental a una población conformada por individuos heterogéneos en todos sentidos, exige no sólo atención en general, sino la especialización de aquellos que sean capaces de generar mensajes en distintos medios tales como escritos, gráficos, sonoros y audiovisuales con el objetivo común de respetar la vida.

La BUAP genera el compromiso con su entorno creando el megaproyecto Universidad y Medio Ambiente (UMA), mismo que busca generar estrategias para el beneficio ambiental, donde el trabajo interdisciplinario se conforma por especialistas de diversas áreas para dar lugar a una propuesta integral.

A nivel institucional, UMA nace bajo la necesidad de cumplir satisfactoriamente con los requerimientos solicitados por el modelo académico-educativo MINERVA (MUM), el cual, busca consolidarse a través de la vinculación social de la institución, y la participación efectiva en el desarrollo regional. La estrategia de comunicación que se diseñó para el proyecto UMA es congruente ante la función social de una universidad pública, que se orienta a través de una formación integral y humanista. 
...transmitir y aplicar el conocimiento crítico e innovador, que permita al mismo tiempo un cambio en las actitudes de la comunidad de la BUAP "Quienes estudien y trabajen en la BUAP tienen el compromiso de cuidar el equilibrio ecológico del medio ambiente no sólo haciendo propuestas, sino también respetando los ciclos naturales de vida y sensibilizando a la sociedad sobre estas problemáticas”. (BUAP, 2007:42).

Con la presencia de UMA, se refrenda el compromiso de la BUAP con la formación de una comunidad universitaria integrada a la sociedad, generando así conocimientos que impacten asertivamente su desarrollo. Por ello, es relevante la puesta en marcha de una estrategia ecológica participativa, informativa y orientadora, que mejore el ambiente. "Quienes estudian y trabajan en la Benemérita Universidad Autónoma de Puebla tienen el compromiso de cuidar el equilibrio ecológico del medio ambiente no sólo haciendo propuestas, sino también respetando los ciclos naturales de vida y sensibilizando a la sociedad sobre estas problemáticas". (Benemérita Universidad Autónoma de Puebla, 2007:42).

El proceso de sensibilización supone la comprensión de una necesidad, y el reconocimiento de un problema, para lo que se propone una solución. En un contexto meramente universitario, se unen la educación y la comunicación para dar forma a un proceso denominado educomunicación, que debe ser considerado como un paradigma o "estilo de ver", de percibir, de conocer y pensar.

La educomunicación pretende la formación de una educación basada en una nueva ética de responsabilidad y respeto al otro por lo diverso, procurando una mejor calidad. Germán Parra (2003) sitúa a la educomunicación, como el camino para construir procesos simbólicos que conducen a la consolidación de formas culturales auténticas y libres donde hay mayor espacio para la participación, la interacción y construcción simbólica de sus pueblos y de su gente. La educomunicación propicia la creación de ecosistemas comunicativos de calidad, promueve una pedagogía de ambiente, e impulsa la formación sociopolítica, tan necesaria para la construcción del sistema mundial más justo y solidario.

El megaproyecto UMA cuenta con el perfil de la sustentabilidad basado en estrategias que soporte la educomunicación traducidas en productos empáticos que persuadan a la comunidad universitaria hacia un fin común en beneficio del medio ambiente, y de su calidad de vida. Todo esto siguiendo el hilo conductor del construccionismo social llamado interaccionismo simbólico donde se construyen significados creativos e interrelaciones compartidas en los mensajes de la campaña de comunicación social, tareas primordiales para los alcances de UMA. 
El megaproyecto UMA requiere de la presentación formal ante la comunidad universitaria para transcender a un conjunto de interacciones benéficas para el ambiente, por lo que se genera el trabajo de comunicación estratégica para la difusión y promoción de la imagen, así como de los trabajos generados en él. El megaproyecto se diseñó para presentarse dentro del campus de Ciudad Universitaria (CU) de la BUAP y poder contribuir en beneficio del cuidado del medio ambiente, a través de la producción de una campaña de comunicación social que permita el posicionamiento de UMA en los universitarios.

A través de la propuesta de comunicación social se generaron los mensajes gráficos y audiovisuales con base en los resultados referidos de la percepción visual manifestada por los universitarios en un diagnóstico previo, fundamentando así el enlace entre el receptor y el medio ambiente a través de los productos identificados con la marca UMA. De esta forma, los diferentes mensajes que acompañen esta imagen serán recibidos de manera satisfactoria y efectiva creando empatía con el estudiante, académico y administrativo de esta universidad.

El objetivo fue diseñar una estrategia de comunicación social dirigida a la comunidad universitaria de la BUAP, para el posicionamiento del proyecto UMA con la finalidad de alcanzar la identidad en la mente del receptor, a tal grado que sea persuadido por los contenidos de una campaña de publicidad con fines sociales que integre todos los elementos necesarios. Para alcanzar este objetivo, fueron necesarias algunas tareas específicas enlistadas a continuación:

1. Diagnosticar la percepción de mensajes en medios masivos por parte de la comunidad universitaria dentro del campus de CU.

2. Crear la comunicación visual y la identidad institucional del proyecto UMA en aplicaciones gráficas como logotipo, imagotipo y sus diferentes presentaciones y variantes.

3. Crear y diseñar estrategias de comunicación en diferentes medios de comunicación.

La justificación de la viabilidad e inversión en recursos materiales, económicos y humanos, está por demás en una situación sustentada por el derecho a la vida. Todo aquel proyecto que tenga como línea de investigación el beneficio para la humanidad debiera ser justificación suficiente para cualquier esfuerzo. La tarea colegiada entre diferentes instancias sociales, políticas y económicas, es un trabajo permanente que bien explica una derrama económica considerable, cuando el resultado será cualitativo y cuantitativo. 


\section{EN BUSCA DE LOS ELEMENTOS COMUNICACIONALES PARA LA DIFUSIÓN}

La manera en que se identificaron los tipos de percepción de los códigos antes referidos en los universitarios, fue a través de instrumentos de medición cuantitativos y cualitativos, dando lugar a un sondeo de la percepción de mensajes mediáticos de la comunidad universitaria dentro del campus de CU, que arrojó la información necesaria para el diseño de imagen institucional de UMA y su aplicación en diferentes piezas gráficas masivas e institucionales, así como la guionización de piezas de radio y audiovisuales para el lanzamiento del megaproyecto, tomando en cuenta las recomendaciones de Paoli (2004) al mencionar que en un proceso de comunicación se necesita tener algún tipo de experiencias similares evocables en común "cuando dos sujetos están juntos y oyen cantar un gallo, los dos pueden evocar su imagen, aunque uno hable zapoteca y el otro inglés" (Paoli, 2004: 56).

La propuesta de una campaña de publicidad con causa social debía conformarse por una serie de mensajes comprendido por un sistema identificable por una población específica, ya que se espera tener impacto favorable en toda la comunidad universitaria.

Considerar a la comunicación como una relación real cuyos términos pueden ser "Dios y las criaturas" o "las criaturas entre sî". En esa relación comunicativa hay dos elementos esenciales, uno de "nexo o conexión" y otro de "donación o entrega". Es lo que indican las expresiones "comunicar a" y "comunicar con" implícitas en el concepto de comunicación, asegurando que "no se puede comunicar a alguien si no hay comunidad entre los términos de la relación" (Galdón, 2001: 74).

James Lull (1997) define a la comunicación como un término que puede entenderse como la transmisión de información a través del tiempo y el espacio, y como la construcción de sentido mediante el intercambio de formas simbólicas. Abraham Nosnik (1995) por su parte, asegura que la comunicación es una manera de establecer contacto con los demás por medio de ideas, hechos, pensamientos y conductas, buscando una reacción al comunicado que se ha enviado, para cerrar así el círculo. 


\section{ANÁLISIS DE DATOS: PERFIL DE LA COMUNIDAD UNIVERSITARIA DEL CAMPUS (CU) BUAP}

Durante una semana fueron aplicados los 650 cuestionarios arrojados para la muestra en toda ciudad universitaria obteniendo los siguientes resultados. La comunidad universitaria BUAP es un grupo social que se caracteriza por su asistencia al turno matutino o vespertino, tomando en cuenta que muchos de ellos comparten horario en los dos turnos pasando entre tres y nueve horas dentro de la universidad ya sea por motivos de estudio, trabajo o convivencia.

Durante estos horarios, la comunidad visita frecuentemente espacios como: Las aulas de clase y cafeterías, lugares donde equilibran tanto horas de estudio, como de convivencia social, sin dejar de lado que a su vez, están obligados a pasar por distintos lugares como: Paradas de autobús y estacionamientos. Ellos dentro del campus y en sus ratos libres, consumen diferentes productos envasados en plástico, unicel, tetra pack, o cartón, así como también consumen productos en pet, lata, envolturas plásticas.

Los factores que obligan a los universitarios a tirar basura fuera de los botes diseñados para tal acción, tienen que ver con la falta de botes disponibles y su lejanía, además existe una frecuente saturación de basura en los contenedores y falta de señalamientos que indiquen donde están ubicados. Aseguran que el motivo que los lleva a tirar basura, es por la falta de mensajes que les recuerde e informe de no hacerlo para contribuir de mejor manera. Esto se manifiesta al mostrar la existencia de diversos diseños de contenedores para basura, lo cual crea en la comunidad universitaria gran confusión al no ubicar uniformidad en el mensaje.

Entre otros puntos, la comunidad universitaria cree que la ausencia de una cultura de clasificación de residuos "orgánicos e inorgánicos" se debe principalmente a la ausencia de conocimiento de los significados de estas palabras, que muchas veces son aplicadas pensando que son entendidas rápidamente por los usuarios. Es por ello necesaria la implementación de anuncios que indiquen su diferencia, información que en la mayoría de las ocasiones es muy difícil recordar. Es importante referir, que otra de las cosas que influyen, tienen que ver con la lejanía y la falta de disponibilidad de estos contenedores, comparada con la de otros de uso general. Aunque aseguran estar consientes de la importancia que tiene clasificar los residuos según su tipo.

Es trascendental señalar que esta comunidad universitaria pudo contestar correctamente la diferencia entre los residuos orgánicos e inorgánicos, gracias a la presencia de elementos visuales que facilitaron el proceso. 
Los alumnos, aún teniendo gran cantidad de contenedores para clasificar, siguen introduciendo sus residuos erróneamente, debido a que muchos de los botes carecen de señalética y otros, que ya están aplicados, no logran transmitir la intención del mensaje debido a su grado de complejidad en el diseño, siendo poco entendible a simple vista, sin olvidar los que se encuentran en mal estado.

Los universitarios pertenecientes al campus de CU, considera que la falta de continuidad en los proyectos ha generado en gran medida la falta de interés para mantener una cultura de cuidado ambiental dentro de la universidad, apoyado de la falta de formalidad en las actividades, demostrando poca credibilidad, que si es sumada a la falta de información, aparece con más evidencia. Por ello, se encuentran muy de acuerdo con la idea de la implementación de un código de ética para el establecimiento de políticas ambientales, además de orientación ecológica a través de cursos realizados por expertos en el tema.

Los alumnos y profesores prefieren las campañas que trabajan bajo perfiles informativos y dinámicos, sin dejar de lado los detalles participativos y con ambientes divertidos, en las que buscan encontrar elementos masivos y promocionales que den vida a la campaña, siempre acompañados de talleres y conferencias, que brinden una información más detallada sobre el tema y problemática.

Dentro de este rubro, la comunidad coincide que los medios impresos y visuales corresponden a uno de los vehículos de información más utilizados para informarse o enterarse de determinada noticia, entre los que destacan: espectaculares, pendones, carteles o posters. A su vez, recuerdan la mayoría de las campañas ambientales, que impactaron no sólo por su sencillez en la información, sino también en las actividades que realizan bajo un seguimiento constante en el cual los resultados son evidentes.

Asimismo, la comunidad apoya la idea del cuidado especial y mantenimiento para las áreas verdes y jardines no sólo de $\mathrm{CU}$, sino de todas las áreas con las que cuenta la BUAP. Además de estar concientes que la presencia de colillas de cigarro perjudica gravemente cualquier área abierta.

"No tirar basura", corresponde a una de las actividades principales con la cual, la comunidad universitaria dice cumplir con el cuidado del medio ambiente. Tomando en cuenta como principales actividades de acción crear áreas de esparcimiento, contenedores clasificados, y reforestación de árboles. 


\section{UBICACIÓN DE PROBLEMÁTICAS DE IMPACTO AMBIENTAL EN EL CONTEXTO DE (CU) BUAP}

Se puede decir que la BUAP en el ámbito comunicacional, cuenta con exceso en diseños de contenedores, muchos de ellos con alguna clasificación en especial, sin uniformidad en diseño visual y coherencia en los mensajes a enviar. La señalética puesta en cada contenedor, se encuentra en mal estado y la elección cromática es desafortunada.

En CU, los estancamientos de agua pueden generar focos de infección, además de que los grandes contenedores, donde finalmente se deposita la basura, se encuentran destapados y en contacto directo con el ambiente. La cantidad de contenedores ecológicos sobre el campus, presenta el problema de que se ubican en sitios alejados, provocando que el universitario busque depositar los residuos de la manera más fácil y rápido. En cuanto a medios de difusión, en CU hay gran demanda de medios impresos que se distribuyen a lo largo de todo el campus. La prensa y revista BUAP no se actualiza constantemente en las estanterías, lo que genera un problema en cuanto a la periodicidad de la revista.

El campus de CU cuenta con un herbario y jardín botánico que dan respuesta a una de las responsabilidades ambientales que tanto ha cuidado la institución, sin embargo, al mismo tiempo alberga un gran número de vehículos que contaminan constantemente; a su vez, existen una gran cantidad de equipos de cómputo conectados a la energía eléctrica, los cuales son necesarios para impartir las clases, acompañados de pantallas eléctricas, focos, lámparas, bocinas, grabadoras y reproductores de cd, copiadoras, scanners, y otros aparatos, los que durante casi 20 horas consumen electricidad. Referente a la realización de actividades y eventos en pro de la ecología, no se cuenta con alguna campaña que informe y oriente acerca de la importancia del cuidado ambiental.

\section{COMUNICACIÓN ESTRATÉGICA PARA EL IMPACTO AMBIENTAL}

La campaña de publicidad con causa social que se propone es resultado del conjunto de investigaciones cualitativas y cuantitativas, cimentadas en la revisión teórica en el tema y las experiencias de campañas previas que le ofrecen a UMA, sustento y confiabilidad como propuesta de comunicación estratégica.

Debido a la finalidad del proyecto, se propuso una campaña de difusión de tipo social, tomando en cuenta la clasificación entre campañas políticas, campañas comerciales y campañas de acción social, donde las dos primeras 
basadas en la comercialización de bienes y servicios, mientras que la tercera es dedicada a la búsqueda de estabilidad o modificación de ideas relacionadas con pautas de conducta y hábitos personales con el fin de obtener un beneficio, tipo de conclusión que se busca para la creación de esta estrategia de comunicación.

Según Jean Jacques Lambin (2003), una estrategia debe apegarse incluso a un ámbito militar, la estrategia de comunicación social que transmite, publica, difunde o promociona ideas alejadas del ámbito comercial, donde el único objetivo es fungir bajo una actitud de utilidad; además debe tener la posibilidad de evaluar las habilidades requeridas y las limitaciones, debe conseguir una ventaja en fuerza, debe evitar la dispersión en los esfuerzos, garantizar la coordinación y coherencia de estos, debe ser flexible ante los imprevistos, y evitar el desperdicio de recurso.

La estrategia de comunicación colectiva, por ende, actúa como acelerador artificial de cambio, tal como lo describen: “...una tecnología de gestión del cambio social que incluye el diseño, la puesta en práctica, y el control de programas orientados a aumentar la aceptabilidad de una idea o práctica social, en uno o más grupos de adoptantes objetivo" (Kotler y Roberto, 1989, p.29).

Por lo tanto, la elección de acciones se centra en una estrategia que debe plantarse en una campaña de difusión. En letras de Socorro Fonseca (2002), la campaña debe alcanzar un conjunto de objetivos y resolver algún problema crucial; una campaña es un sistema de comunicación que coordina una serie de esfuerzos encaminados a obtener un resultado.

Dentro de los objetivos primordiales de trabajo que se propone para la campaña UMA se encuentran: 1 ) influir en los universitarios; 2) contar un principio, un desarrollo y un final; 3) ser omnipresente; 4) funcionar con base en estrategias de comunicación persuasiva; 5) profesionales y equipos de trabajo en diversas áreas estarán a su cargo; 6) utilizará medios de comunicación; 7) recursos económicos y/o patrocinios; 8) los públicos se analizarán profesionalmente y motivados a participar; 9) ser gradual, por lo que exigirá tiempo y esfuerzo.

\section{UMA: LA IDENTIFICACIÓN}

Como en toda campaña, existe un orden, tiempo y forma que debe ser respetado para que los resultados se obtengan satisfactoriamente, y lo importante después de decidir qué tipo de campaña usar, es ubicar la estructura para su desarrollo, la forma en que se dividirá cada una de sus fases para lograr alcanzar todos los resultados. 
La campaña de publicidad con causa social UMA, se basa en el modelo en cinco etapas: 1) identificación; 2) legitimación; 3) participación; 4) penetración y; 5) distribución. De acuerdo con los objetivos de investigación previamente vistos, esta campaña cumplirá con la tarea de cubrir la primera etapa de difusión del megaproyecto Universidad y Medio Ambiente, donde se pretende lograr la identificación de UMA por la comunidad universitaria. Por ello, la primera etapa trabaja con el propósito de lograr que los integrantes de la comunidad inicien una actividad de identificación y reconocimiento a través de la percepción del logotipo, símbolos e imágenes empáticas reflejadas en lemas aplicados a diversos productos promocionales como uniformes, camisetas, gorras, banderas, papelería congruentes con la idea y objetivo a alcanzar.

Para iniciar con la identificación de la comunidad universitaria con UMA, es necesario ubicar la definición del mensaje, donde en primera instancia se expone el nombre UMA, un conjunto de siglas (elegido previamente ya por las autoridades correspondientes) que como Ries y Trout, (2005) sugieren, cuentan con una ventaja fonética y visual logrando quedar inmerso en la memoria de los integrantes de la comunidad. Con respecto a su significado, UMA, corresponde a la forma de relacionar y ligar la responsabilidad ambiental que la universidad tiene con el cuidado y mantenimiento del mismo.

Ries y Trout (2005) comentan que el simple hecho de lograr ser el primero, te regala la ventaja de aparecer más fácilmente en la mente del receptor y de que un segundo pierda la oportunidad de ser recordado. UMA cuenta con esa ventaja, puesto que corresponde a la primera campaña integral de cuidado ambiental existente en la universidad. Los integrantes de la comunidad universitaria, buscan claridad y facilidad en los mensajes, ante lo que UMA, con un nombre fácil de mencionar, de recordar, de visualizar y corto, es fácil de memorizar.

La identidad UMA, fue creada en función de la institucionalidad que por varios años ha manejado la BUAP, respetando los lineamientos de un diseño sobrio, limpio, y siempre cercano a la comunidad universitaria. Después de elegir un nombre es necesaria la aplicación de los elementos de la comunicación visual, que complementen la fase del nombre y su lanzamiento, ya que uno de los objetivos que tiene, es la conciliación progresiva de formas, colores, tipografía y espacios, con la personalidad de la empresa encontrándose directamente relacionada con lo que se conoce como identidad y diferencia corporativa.

Un mensaje construido con la intención de hacer conciencia sobre una conducta puede ser más eficaz cuando se aplican elementos que son reconocibles para el receptor. Esto es, usar símbolos que le signifiquen 
experiencias o situaciones fácilmente reconocibles. Blumer (1982) define esto como el interaccionismo simbólico, un enfoque teórico que se refiere al estudio de la vida de los grupos humanos y del comportamiento del hombre.

Este enfoque puede explicarse de la siguiente manera. El ser humano actúa con respecto a las situaciones o cosas de acuerdo con lo que significan para él, lo que emana de situaciones y convenciones sociales a través de una interacción con los demás. Lo más importante es la interpretación personal que el receptor le da a la información recibida manipulándola incluso para darle significados en un proceso que el propio Blumer (1982) menciona como autointeracción.

La tipografía elegida para UMA, es de diseño original basada en un sólo trazo por tipo, es decir, por letra: Un trazo sencillo, sin patines, con fuste grueso e interespaciado simple para lograr una fácil compresión. Esto la hace de simple lectura, e impide las ligaduras entre las letras lo que podría generar confusión, es de fácil escritura, y reconocible ante cualquier nivel académico del receptor, puesto que no debe olvidarse que la intención de UMA a largo plazo, es impactar a nivel social.

Este logo cuenta con un elemento simbólico dinámico, el primer tipo, o la primera letra, cuenta con una estructura diferente a las demás, ya que tiene como objetivo una doble función, servir como imagotipo, elemento que dentro del logo puede ser utilizado como unitario para reforzar la identificación de la campaña, y como función fonética al sonar como la letra alfabética "u" lo requiere en el nombre UMA, con lo que se retoma lo que Abelardo Rodríguez (2002) comenta al referirse a que un tratamiento tipográfico, con un diseño específico de la razón social de una empresa o institución alcanza una personalidad diferente y propia.

Figura 1. Logotipo UMA.

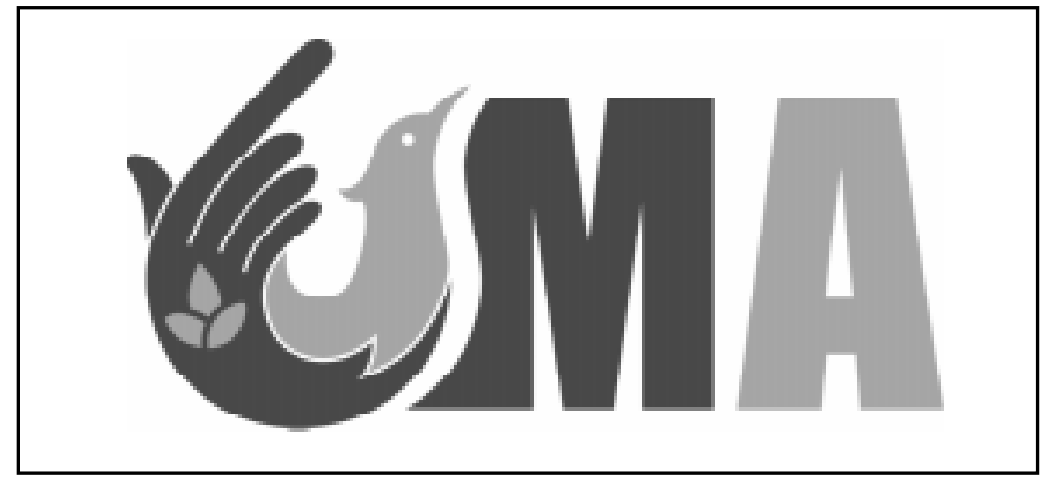

Fuente: Elaboración propia. 
El logotipo tiene una vertiente dentro sí mismo que sirve para facilitar el proceso de identificación en una campaña, por ende, el imagotipo corresponde a un conjunto de signos que al unirse producen un símbolo, o representación gráfica: UMA, este logo se puede apreciar en la figura 1. "El símbolo, al igual que el logotipo, ejerce una función identificadora, el logotipo presenta directamente al nombre en forma escrita, el símbolo ejerce una función más compleja y sutil, ya que presenta la noción más abstracta de la misma marca" (Costa, 1993, p.87).

\section{LEMA INSTITUCIONAL Y SLOGAN DE CAMPAÑA}

La identidad de toda campaña, además del refuerzo visual, va acompañada de un refuerzo fonético pero no sólo visto en el nombre, sino también en el lema y slogan que acompañarán su posicionamiento. Por ello, para esta campaña, fueron creadas un conjunto de frases que pretenden complementar la identidad de UMA y lograr así, el impacto esperado.

Con el fin de continuar con la unidad en la campaña y reforzar el impacto de la estrategia de comunicación, el lema institucional "UMA, solución con rumbo", deberá ser aplicado durante todas las etapas junto con los correspondientes slogans de campaña. El slogan de la campaña de lanzamiento, "UMA, somos todos", busca involucrar y crear una primera inclusión a la comunidad universitaria hacia temas de interés colectivo como lo es el cuidado ambiental del campus de Cu bajo una frase de dos palabras que logre fácilmente persuadirlos.

CuAdRo 1. Frases de la campaña UMA.

\begin{tabular}{|l|l|}
\hline \multicolumn{2}{|c|}{ Frases UMA } \\
\hline Lema institucional & "UMA, solución con rumbo" \\
Slogan de campaña de lanzamiento & $\begin{array}{l}\text { "UMA, somos todos" } \\
\text { "Limpiar es un acto inteligente" } \\
\text { "Ahorrar es un acto inteligente" } \\
\text { "Clasificar es un acto inteligente" }\end{array}$ \\
& $\begin{array}{l}\text { "Reforestar es un acto inteligente" } \\
\text { "Ayudar es un acto inteligente" } \\
\text { "Cuidar es un acto inteligente" } \\
\text { "Respetar es un acto inteligente" }\end{array}$ \\
\hline
\end{tabular}

Fuente: Elaboración propia. 
Como menciona Mariano R. Castellblanque (2001), uno de los objetivos primordiales en la comunicación persuasiva es el tratar de convencer al receptor de algo, y en el caso de UMA, hacerles entender que la tarea del cuidado ambiental no es responsabilidad de una persona o grupo, sino de todos. El slogan resume el mensaje publicitario con las menos palabras posibles con el fin de que el emisor recuerde y memorice su significado, alcanzando así el posicionamiento esperado por el investigador o responsable.

De acuerdo con ese mismo autor y Enrique Ortega (1999), los medios de comunicación convencionales son los conocidos como above the line, y corresponden a los medios que se caracterizan por opacar tradicionalmente la mayor parte de las inversiones de los anunciantes: la prensa, la radio, la televisión, el cine y el medio exterior. Por otro lado, los medios de comunicación no convencionales below the line, forman un conjunto más amplio y heterogéneo de medios publicitarios que con el paso de los años, han ido acaparando la atención como resultado de las mayores inversiones de las que han sido objeto.

Con esta premisa, en el caso UMA, ambos tipos de medios son útiles para la difusión. La prensa en forma primordial por su permanencia y viabilidad de ubicación en las instalaciones de ciudad universitaria, sin embargo, el internet también es un medio con gran penetración debido al alcance que logra entre la comunidad estudiantil y académica ya que la mayor parte del día está cerca a un medio de este tipo durante la semana.

Para esta campaña en la etapa de difusión del lanzamiento del proyecto UMA, es muy importante considerar la selección de medios necesaria para lograr servir como vehículo que lleve consigo el mensaje, llegando sin mayor problema a la meta o destino determinado. Por ello, el siguiente paso dentro de la estrategia es la selección de los medios de comunicación, una elección que sin duda corresponde a uno de los elementos fundamentales a tomar en cuenta para el lanzamiento de la campaña, ya que de éstos dependerá en gran medida la aceptación o rechazo del mensaje recibido de parte de los estrategas.

La investigación hecha arrojó que los medios impresos son los preferidos por la comunidad universitaria. Existen diferentes medios impresos que circulan en el campus de CU de la BUAP, las cuales se encuentran ya bajo el gusto de la comunidad universitaria, tales como "Chidobuap" y Estudiantes". Los medios impresos gratuitos tienen una ventaja enfrente a los demás medios gracias a su fácil acceso, son permanentes y se pueden transportar.

Para esta estrategia es fundamental llegar rápidamente al público sin mayor inconveniente y, por ello, el medio visual corresponde a una de las 
opciones más efectivas, de ahí que, las acciones que se proponen para la aplicación de la estrategia de medios impresos se resumen en:

1. Los pendones estarán en los pasillos de los edificios de cada facultad a la vista de los integrantes de la comunidad universitaria.

2. Los carteles se encontrarán en todas y cada una de las pizarras generales de las facultades y pasillos.

3. Se utilizarán todas las vallas y espectaculares existentes en las facultades del campus universitario para la puesta de los impresos.

4. La señalética de separación de residuos (ver figura 2), vendrá incluida en todos los contenedores de basura, pasillos, aulas y auditorios del campus universitario.

Figura 2. Propuesta gráfica para contenedores de basura.

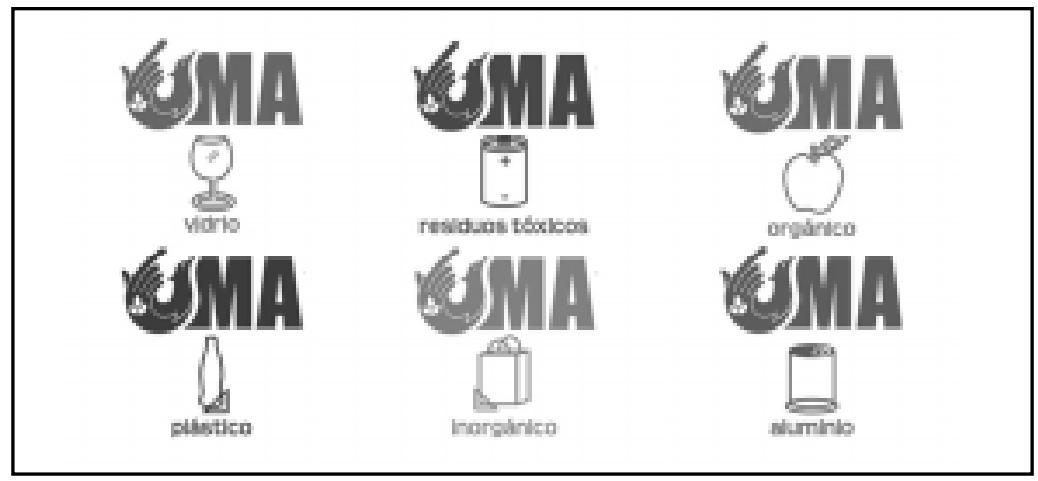

Fuente: Elaboración propia.

El internet sin duda resultó un excelente medio de comunicación entre la comunidad universitaria, por lo que se incluyó como una de las estrategias de difusión del proyecto más eficiente debido a la empatía y acceso constante a la web, por lo que se diseñó el portal a partir de los elementos arrojados en el diagnóstico, ubicándola en la dirección www.universidadymedioambiente.buap.mx

La página web asegura mantener la atención del cibernauta, esto se refiere a que se logrará captar la concentración de la mente sobre los estímulos visuales, tipográficos y de contenido, preparando así al universitario para la percepción de la misma. Para ganar la atención Costa (1993) nombra varios estímulos que pueden funcionar para acompañar al mensaje: El tamaño, el color, la intensidad, el contraste, el emplazamiento, el ruido/la 
música, el movimiento, el aislamiento y la novedad. Este medio de comunicación está a disposición de toda la comunidad universitaria para la actualización de información, de ofertas académicas sobre el tema ambiental, y de piezas gráficas para su ilustración.

Una de las formas para poder expresar mensajes es por medio de la comunicación audiovisual; Jesús Bermejo (2005) explica a la comunicación audiovisual como todo intercambio de mensajes entre personas a través de un sistema tecnológico sonoro y/o visual. La cual se diferencia de la comunicación cara a cara porque existe siempre una mediación tecnológica. La naturaleza de la televisión la define como un medio audiovisual que transmite mensajes a las audiencias heterogéneas y dispersas. Esta universalización se debe a que el receptor no necesita saber leer o tener un determinado grado de lectura.

La televisión cuenta con el poder de transmitir de forma instantánea la información, dramatizar o trivializar los hechos dando importancia al tiempo televisivo como un valor intrínseco, sin olvidar también, que logra implicar a la audiencia de manera total, ya que está pendiente de ellas en casi todos los sentidos. Dentro de las actividades pensadas para este medio se propone la creación de spots televisivos con una duración de 20 segundos, la inserción de los spots en la página de internet UMA, y la inserción de los spots en BUAP TV.

La radio es un medio con ventajas como ser compañía, física y emocional del receptor, sólo requiere de atención de un sentido, el auditivo; es un vehículo persuasivo, además de ofrecer inmediatez y sensación de proximidad. El amplio lenguaje de la radio puede compensar en ocasiones la carencia visual, y a través de los efectos sonoros, la música, las voces diferentes, los ruidos y trucajes, distorsiones y otras combinaciones, consigue impacto en la comunicación publicitaria.

Aunque la BUAP internamente en el campus no cuenta con un sistema de circuito cerrado de audio, tiene la estación 96.6 FM por donde transmite diferentes programas a través de Radio BUAP, y donde se propone insertar spots informativos con el sello de la marca UMA. Abrir mayor cantidad de programas de servicio social, prácticas profesionales, becas, investigaciones de tesis, maestría y doctorado ayudará a ganar mayor fuerza de trabajo e interés en alumnos, profesores e investigadores sobre la importancia de trabajar en pro del cuidado ambiental. Otra propuesta es incluir en el calendario escolar fechas en conmemoración del medio ambiente y su cuidado, como por ejemplo "la semana verde", días en los que se realicen diferentes actividades en beneficio de la ecología, donde se invite a conferencias de expertos en el tema. 
Aprovechar los espacios que ya están en CU, como hacer visitas guiadas al herbario y jardín botánico de la BUAP a alumnos de prepa y licenciatura, para invitarlos a una Expo Ambiente donde participen con videos, spots de tv y radio, carteles y diversos talleres. Es necesario realizar un estudio minucioso sobre el nivel de contaminación en Ciudad Universitaria y sus calles aledañas, y planear así, talleres informativos sobre separación de residuos y aprovechamiento de recursos, para que con base en esa capacitación las estrategias de comunicación alcancen los objetivos.

\section{PANORAMA UMA}

La BUAP además de apostarle a lo académico le apuesta a la mejora de la calidad en su ambiente cotidiano, futuro de los seres humanos con el respeto, el control y el cuidado de los recursos naturales. Sin duda, UMA espera lograr dentro de esta primera fase, que los integrantes pertenecientes a la comunidad universitaria inicien una mejora de su calidad de vida, abarcando desde las aulas de clase hasta los lugares de trabajo, contribuyendo de manera activa y rápida en la clasificación de residuos, al reconocer el megaproyecto a través de esta campaña.

El estudio de investigación realizado arrojó datos sobre las causas que originan la falta de interés de los integrantes de la comunidad universitaria sobre su preocupación por el ambiente, por ello, a través de este trabajo fueron diseñadas diferentes estrategias que difunden las causas que sigue UMA, estrategias que se deben ajustar con la aparición de nuevas conductas y necesidades.

Cabe señalar la emergencia por destinar presupuesto a cuestiones ambientales dentro de Ciudad Universitaria de la BUAP, con lo que el compromiso de UMA será motivar a la comunidad a participar voluntariamente en el cuidado y clasificación de residuos dentro del campus, evitando que se conviertan en individuos que dañen su entorno.

La estrategia de comunicación UMA deberá trabajar muy de cerca con el apoyo de cada una de las instancias pertenecientes a la comunidad, bajo un ambiente de efectivos canales de comunicación internos y externos. Se debe resaltar que si se omite la importancia de un departamento de comunicación y logística que monitoree el avance de la campaña, el proceso de desarrollo y evolución de la misma quedará estancando por la falta de seguimiento y continuidad del proyecto. 


\section{FUENTES REFERENCIALES}

Benemérita Universidad Autónoma de Puebla. (2007) Modelo Universitario Minerva (Documento de Integración). Puebla, México: BUAP

Bermejo, J. (2005) Narrativa audiovisual: Investigación y aplicaciones. Madrid: Ediciones Pirámide.

Blumer, H. (1982). El interaccionismo simbólico: Perspectiva y método. Barcelona: Edit. Hara.

Costa, J. (1993) Reinventar la publicidad: Reflexiones desde las ciencias sociales. Madrid: Editorial Fundesco.

Fonseca, Socorro. (2002). Diseño de campañas persuasivas. México: Prentice Hall.

Galdón, G. (2001). Introducción a la información. España: Ariel Comunicación.

Kotler, P. \& Roberto, E. (1993). Mercadotecnia social. México: Editorial Diana.

Lambin, J. J. (2003). Marketing estratégico. España: ESIC.

Lull, J. (1997). Medios de comunicación, cultura - aproximación global. Buenos Aires: Amorrortu Editores.

Nosnik, A. (1995). Comunicación corporativa. México: Trillas.

Ortega, E. (1999). La comunicación publicitaria. Madrid: Pirámide.

Paoli, J. (2004). Comunicación e información, perspectiva teórica, México: Trillas.

Parra, G. (2003). Bases epistemológicas de la educomunicación. Quito, Ecuador: Abya Yala.

R. Castellblanque, M. (2001). Estructura de la actividad publicitaria, de la publicidad de la a a la z, España: Paidos.

Ries, Al \& Trout, J. (2005). Posicionamiento: La batalla por su mente. México: Mc Graw Hill.

Rodríguez, A. (2002). Solo para estrategas, México: Editorial Trillas. 